\title{
The Sympoiesis of Superheroes
}

\section{Per Israelson}

In the following I want to address the posthumanist and participatory aesthetics of the comic book Black Orchid (1988), written by Neil Gaiman and illustrated by Dave McKean.

Through the neocybernetic concept sympoiesis, the comic book Black Orchid can be understood as a media ecology, where the feedback between the reader and the material environment of the comic book emerges as a distributed cognition. I will argue that the reader of the comic book participates in the production of aesthetic experience, and, more importantly, that this participation is not only a question of joining in on the hermeneutic circle, where the reader interprets the comic book and cre-

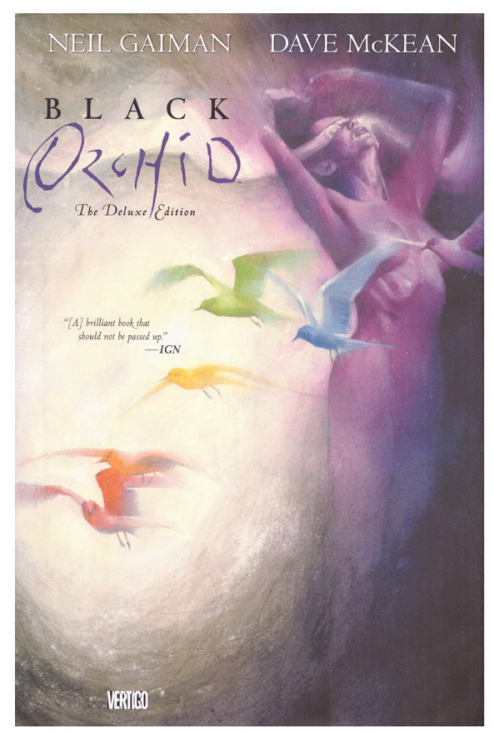


ates a storyworld. From a media-ecological perspective, aesthetic participation is also material and embodied; it is a question of participating in the emergence of an environment. In such a reading, Black Orchid tangibly stages an act of becoming, an event of ontogenesis.

The superhero character Black Orchid was introduced in the DC line Adventure Comics in 1973. In its original run Black Orchid comes forth as a typical crime fighting superhero of the detective comics variety; working in an urban setting, she is an adamant supporter of the disenfranchised, protecting their civic rights against the ruthlessness of crime bosses. Although her superpowers stem from the fact that she is a plant-human hybrid, the anthropocentric ideology of the comic is never interrogated. The morals of the original Black Orchid are without question grounded in a liberal humanist ethos.
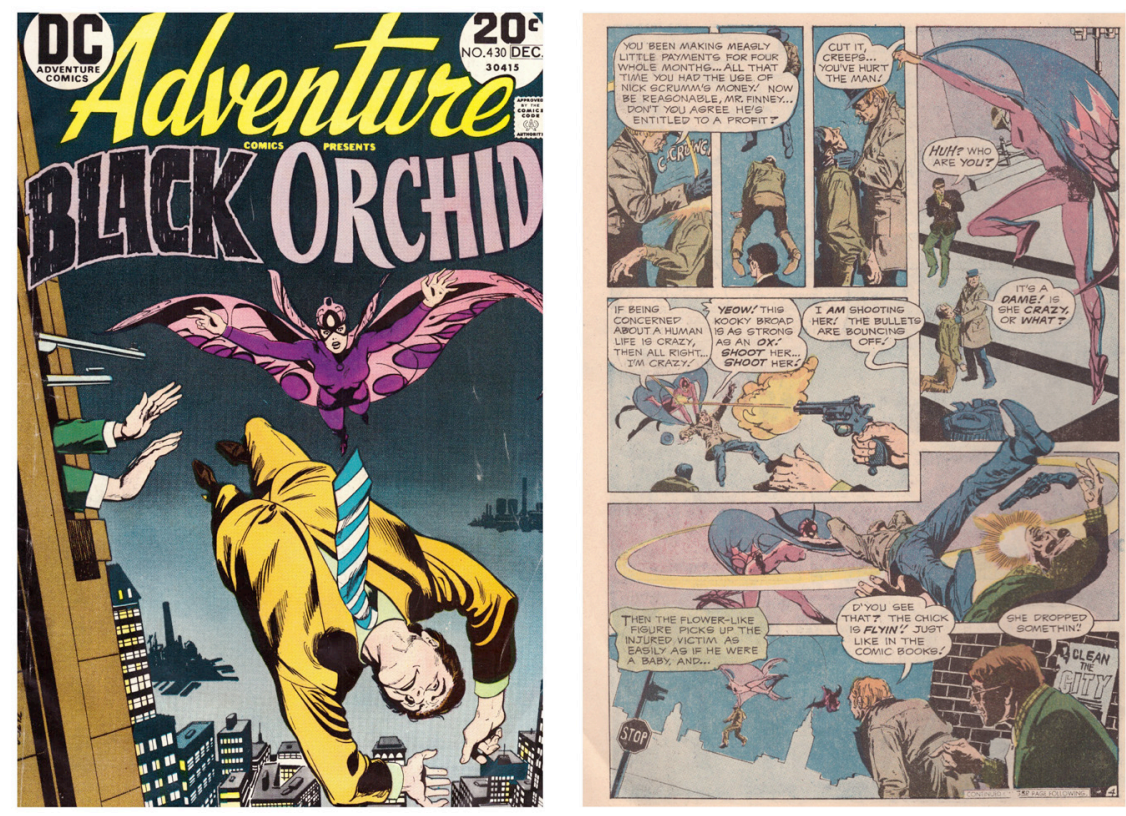
In 1988, Black Orchid was rebooted by Neil Gaiman and Dave McKean, on commission by DC editor Karen Berger. Gaiman and McKean wrote three issues, later to be collected in trade paperback under the Vertigo imprint, and Black Orchid was picked up as a single title that ran for 20 issues in the early 1990 s. The Vertigo Black Orchid is closely aligned to the deconstructive aesthetics of the 1990s revisionary style of superhero comics; self-referring and metafictional it strongly focuses on the processes of narration and creating storyworlds.1
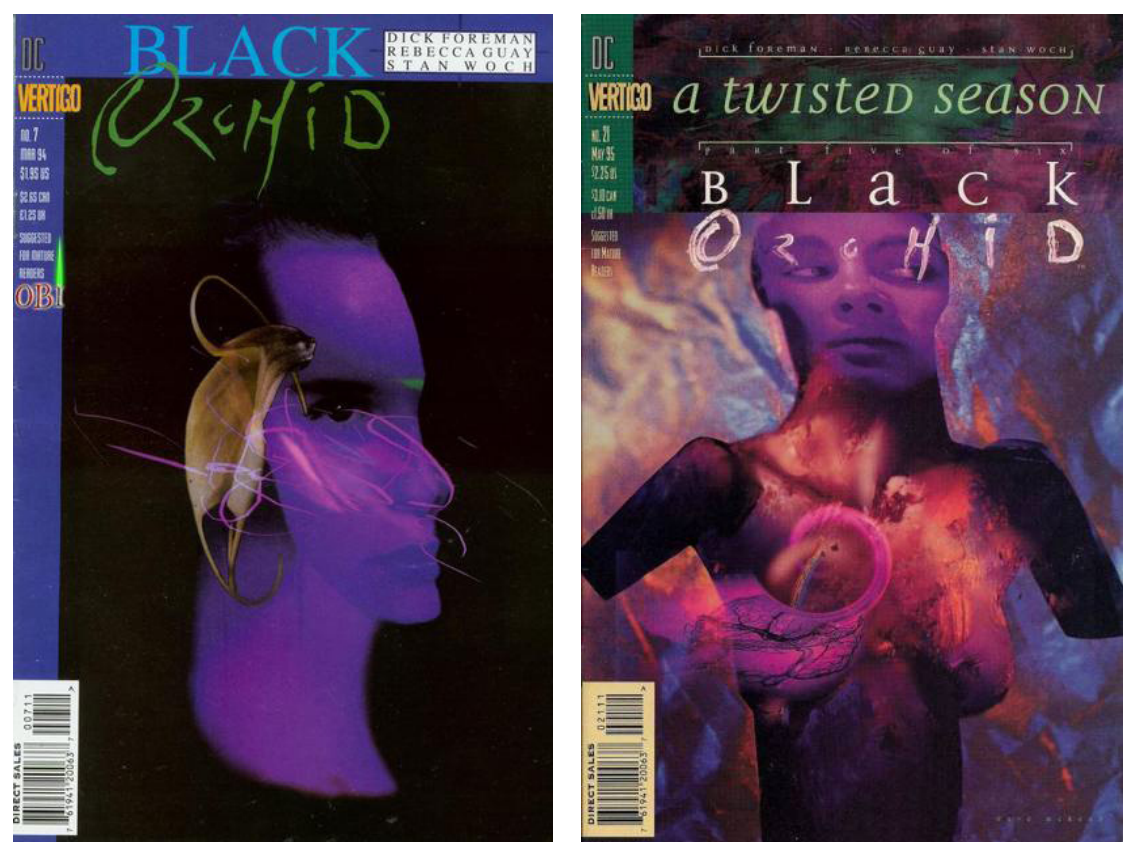

With the recent all over reboot of the DC timeline, the so-called New 52, Black Orchid has been grouped together with the occult Justice League Dark, headed by John Constantine. Here Black Orchid once again seems returned to a more conventional superhero identity.

1 For a discussion on revisionary superhero comics and deconstructive aesthetics, see Geoff Klock, How to Read Superhero Comics and Why (New York: Continuum, 2002) 

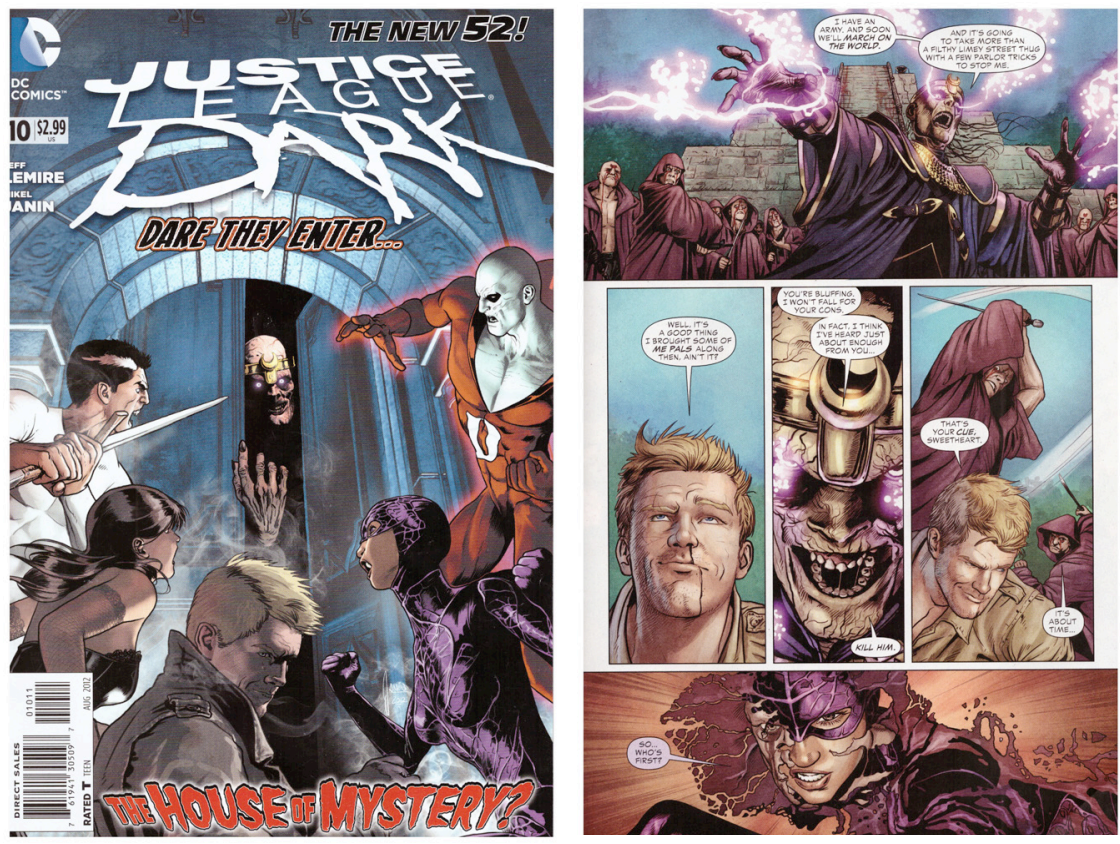

Framing the superhero genre as a media ecology, the 1988 reboot of Black Orchid could be described as an event of cybernetic feedback, where a new organization is configured from an already existing cultural environment, while at the same time reconfiguring that environment. Here, Gaiman and McKean explicitly thematize the fluid identity of the character Black Orchid, making the plant-human hybridity a central tenet of the narrative. In the reboot, the memory and personality of the character Black Orchid is not a transcendental unit that could be transferred from one version of the character to another, but rather it is grounded in a material environment. From a metanarrative position, Gaiman and McKean's Black Orchid comments on the reboot logic of the superhero genre, in which superhero characters are adapted to new cultural environments in order to generate new viable commodities.

Thus, the event of configuration is a prominent feature in the 1988 reboot of Black Orchid. But, as we shall see, the reading of the comic book Black Orchid also focuses on material configu- 
ration. The reading situation here becomes an embodied practice, not only a matter of interpreting, as an autonomous and disinterested subject, a foreign body of information, but also a matter of embodying the perceptions and experiences produced by the material properties of the comic book. And while it certainly could (and perhaps should) be argued that every form of reading, to some extent, is an embodied practice, it is nevertheless the case that the aesthetics and the reading practice of the comic book - in which movement and touch play an important part - explicitly stresses sensation as an emergent property. Accordingly, and following N. Katherine Hayles, it could be argued that the embodied perception - and consequently the meaning production - of Black Orchid hinges on the materiality of a given situation: it is cognition situated in the material.2 It is in this fashion that the reading of Black Orchid comprises a posthumanist experience.

In her latest book, Staying with the Trouble: Making Kin in the Cthuluscene, Donna Haraway proposes the concept of sympoiesis as a model for describing the emergence of embodied experience, comporting with her earlier theories of feminist-cyborg subjectivity, situated cognition and the becoming-with of companion-species. Haraway writes:

'Sympoiesis is a simple word; it means 'making-with.' Nothing makes itself; nothing is really autopoietic or self-organizing. In the words of the Inupiat computer 'world game,' earthlings are never alone. That is the radical implication of sympoiesis. Sympoiesis is a word proper to complex, dynamic, responsive, situated, historical systems. It is a word for wordling-with, in company."3

2 "In contrast to the body, embodiment is contextual, enmeshed within the specifics of place, time, physiology, and culture, which together compose enactment. Embodiment never coincides exactly with 'the body', however that normalized concept is understood. Whereas the body is an idealized form that gestures toward a Platonic reality, embodiment is the specific instantiation generated from the noise of difference.", N. Katherine Hayles, How We Became Posthuman: Virtual Bodies in Cybernetics, Literature, and Informatics (Chicago: University of Chicago Press, 1999), p 196

3 Donna Haraway, Staying with the Trouble: Making Kin in the Cthuluscene (Durham: 
The theory of sympoiesis can be described as a neocybernetic and ecological interpretation of the theory of autopoiesis. Initially presented by Humberto Maturana and Francisco Valera in their co-authored study Autopoiesis: The Organization of the Living (1973), the theory of autopoiesis describes how not just informational systems but even living systems, function cybernetically.4 According to the theory of autopoiesis, living organisms are operationally closed, and relate to the environment in which they are enmeshed as an observing system. However, the environment - and an external, objectively existing world - does not pre-exist an observing system, observation rather comes about following a set of interactive processes determined by the organization of the system. Thus, the theory of autopoiesis stresses perception as an act of creation. But while the perceptual apparatus is organized in relation to an environment, this relation is altogether internal to the observing system and determined by that system's own organization. Paradoxically, then, it would seem that the organization of living systems determines the environment, while at the same time being open to feedback from that very same environment. By creating their environments, organisms are created by the environment.

From a neocybernetic perspective, Mark Hansen has described this paradoxical environmental feedback as a system-environment hybrid.5 In neocybernetic systems-theories the relation between systems and environments is generally situated in the function of organizational closure. Thus, these theories argue that one should understand autonomy as a system that is structurally coupled to an environment, and with other systems, by way of organizational closure. Accordingly, reading the comic book spread of Black Orchid is, from a neocybernetic point of view,

\footnotetext{
Duke University Press, 2016), p 58

4 Humberto R. Maturana and Francisco J. Varela, Autopoiesis and cognition: the realization of the living (Dordrecht: Reidel, 1973), Originally published in Chile as De Maquinas y Seres Vivos, in 1972

5 Mark B. N. Hansen, "System-environment hybrids", in (eds.) Bruce Clarke \& Mark D. Hansen Emergence and Embodiment, New Essays on Second-order Systems Theory (Durham \& London: Duke University Press, 2009), p 115
} 
an emerging event, where the subjectivity generated hinges on a self-regulating and self-observing system that in turn prescribes the conditions under which the material environment (that is the comic book, as well as reader, movements of body and pages, and so forth) comes into being. Once coupled to the comic book spread, reader and comic book alike become part of a systemenvironment hybrid. It is the sympoiesis of system-environment hybrids, this co-production of perception that I wish to highlight in the following. This is how Black Orchid creates world.

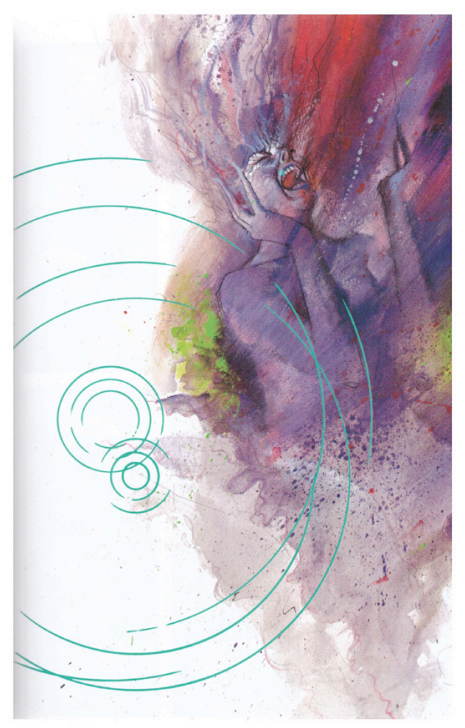

The opening sequence of Gaiman and McKean's Black Orchid culminates with a scream. It is, since we are dealing with the comic book medium, by necessity a silent scream. This silence is also stressed by the absence of captions. However, the strong presence of sound and the voice as a medium, even if it is only alluded to in the negative, points to the manner in which the narration establishes itself as a series of complex sensory events. These events, understood as system-environment hybrids, invite reader participation and sympoietic configuration by producing the embodied experience of reading. Text and reader are implicated in the plant-human hybridity of the Black Orchid character: in essence both text and reader are taking part in the becoming of a hybrid identity. As we shall see, reading Black Orchid here becomes a matter of participating in the memory process of a distributed subjectivity.

Some pages earlier in the opening sequence, the crime fighting Black Orchid has been murdered by the crime syndicate she is infiltrating. The scream, in a spread that leads up to a single image occupying a whole page, marks the rebirth of one of Black 
Orchid's plant-human hybrid bodies, stored and cultivated in a green house on the outskirts of the vast urban sprawl of Metropolis. Subsequently, the plot of Gaiman and McKean's reboot

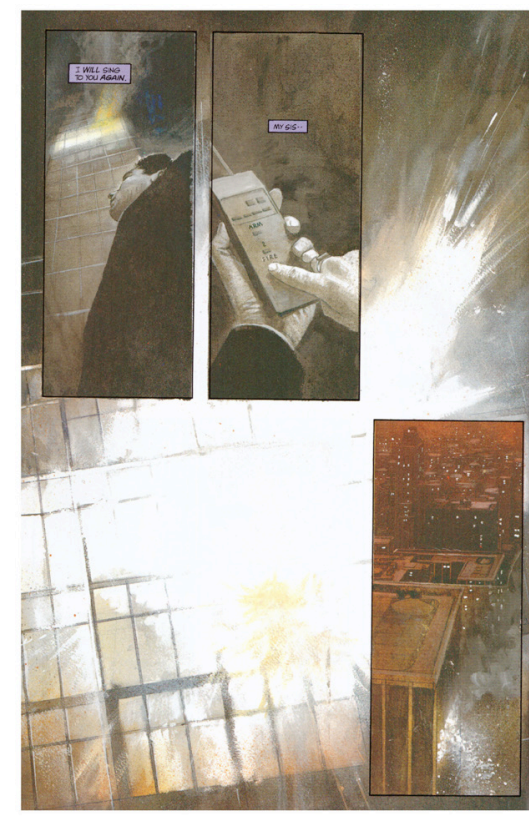
focuses on the emergent identity of the reborn version (or rather versions, as it soon becomes apparent that another, younger version also has been reborn) of Black Orchid. On the one hand, it would seem that each discrete plant-human body is the same as the other, sharing not only DNA but also a materially stored memory and a personality of sorts. On the other hand, the reborn Black Orchid has only a vague recollection of the experiences of her previous version, and a large part of the narrative of Black Orchid is devoted to - in the manner of a private investigator - collecting clues and tying together pieces of information into a coherent story. To this end, Black Orchid visits sites and characters well known to the reader of DC comics, questioning denizens of Arkham Asylum, such as the plant-based super-villain Poison Ivy, as well as receiving advice from Batman, before finally meeting up with Swamp Thing in the Louisiana Bayou. Here, in the "green" which is the living world-body of Swamp Thing, and which encompasses all living plants on Earth, Black Orchid learns about her past. As Swamp Thing traces the memories stored in her "cell spirals", Black Orchid - and the reader of course - learns, that she is the product of an experimental merging of the RNA and DNA taken from a woman called Susan Linden with the genetic material of various orchids. She also learns that the botanist in charge of the process, Philip Sylvain, apparently had been secretly in love with Susan. After her gangster ex-husband Carl Thorne had murde- 

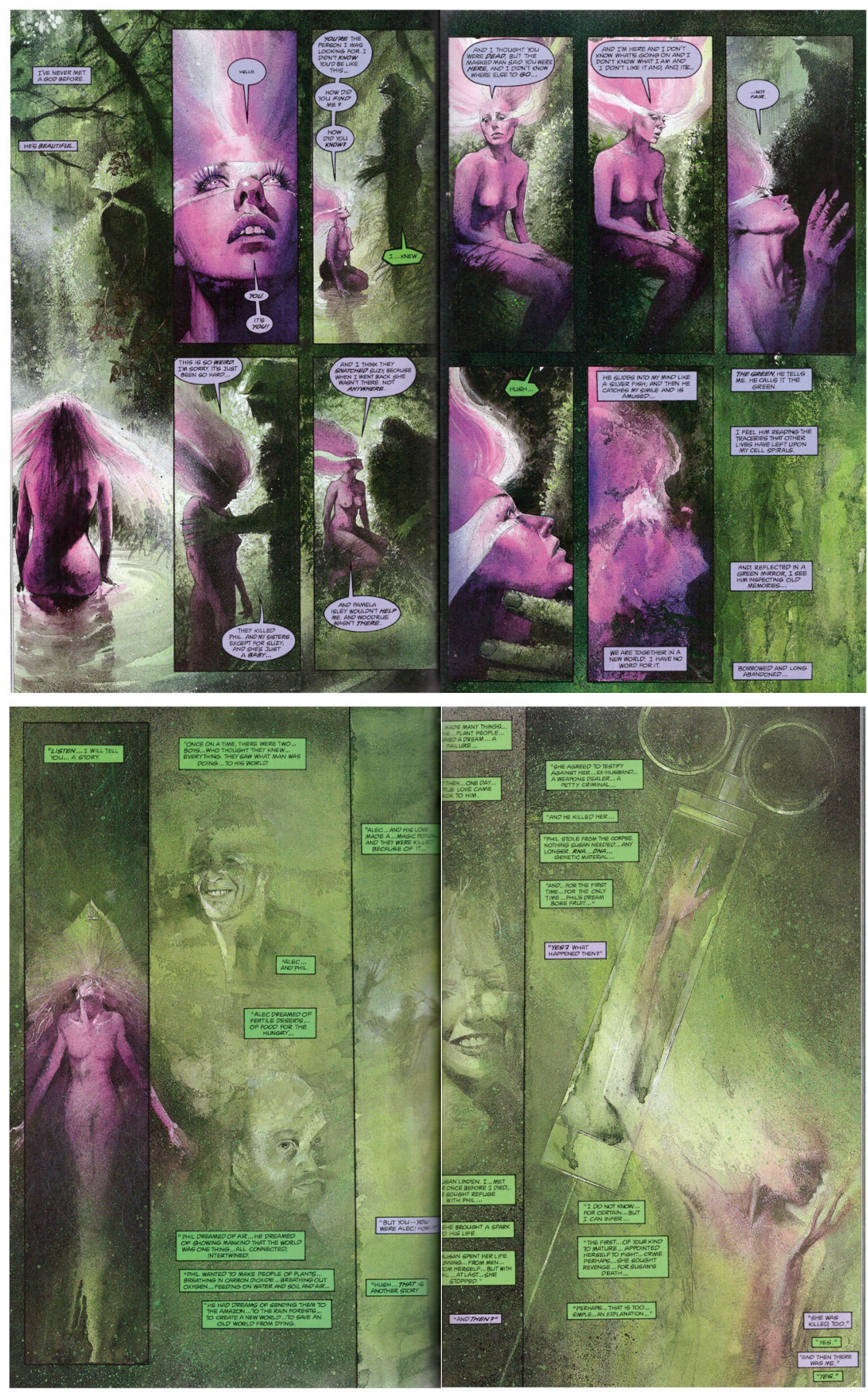
red Susan - she was about to testify in a trial against him - Philip seems to have taken the opportunity to satiate two of his most pressing urges in life, an erotic desire towards Susan and a desire to create plant people.

The appearance of Swamp Thing clearly illustrates, both on a visual and a thematic level, the emergence of a system-environment hybrid. Rebooted by Alan Moore in 1982 - also under editor Karen Berger - Swamp Thing, created by Len Wein and Bernie Wrightson in 1971, had been transformed from an enlightened and humanist environmentalist superhero, defending the "green" from the ravages of industrialized modernity, into a posthumanist, ecocritical creature not only defending but essentially being and embodying the "green". In the original 1971 version of Swamp Thing an experiment gone wrong turned the young scientist Alec Holland into the monstrous plant-being Swamp Thing. In other words, the original comic book Swamp Thing featured a human become plant, but essentially still with a human psyche and personality. Moore's reboot tips the ontology of Swamp Thing on its head. No longer a human transformed into a plant; in Moore's version, it is the swamp itself that has absorbed the body and memories of Alec Holland. A plant has absorbed the human, but is still essentially thinking and behaving as a plant (however that might be). Closely aligning their version of Black Orchid to Moore's Swamp Thing, Gaiman and McKean cast the narrative in a similar, posthumanist and ecocritical mould. But looking at the actual sequence in which Swamp Thing presents himself to Black Orchid, it is also clear that this emergent and environmentally grounded identity is situated in the material properties of the comic book. And perhaps more importantly, in the manner in which the comic book spread, by subverting and transgressing the distinctions between narrative units, emphasizes perception as an event of configuration, in which both reader and comic book alike participate. This is most clear in how the sequence organizes the panels and the gutters between the panels, eventually overthrowing the relation between background and foreground. 
The first page of the sequence, in which Black Orchid is slowly awakening after crashing into the Louisiana Bayou, enacts the emergence of a grid structure, materially emphasizing the return

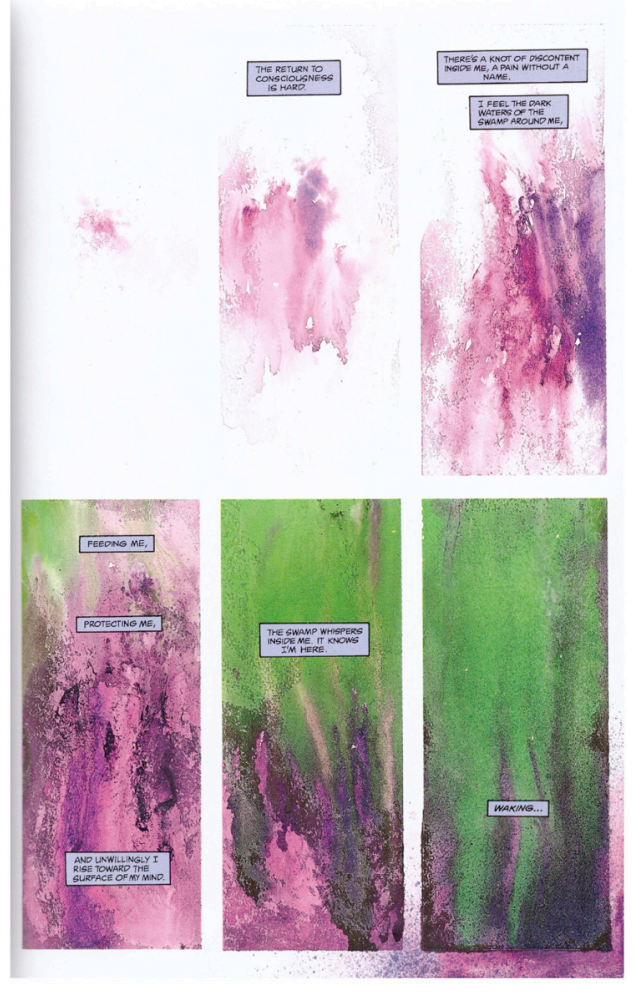

to consciousness and an ordered reality. In a sense, the wakening of Black Orchid coincides with the organizational structure of the medium. In the following spread, this grid structure, in which the gutters between panels have a predominantly sequential function, establishing a reading dominated by temporal progression and movement, is both enforced and countered. The spread is framed on two sides by the faces of Black Orchid and Swamp Thing, respectively, effectuating a circular movement, enfolding the reader within the environment of the medium, within the expanse of the spread. This spatial effect marks a site of perception where the presence of the aesthetic experience - of the world generated by the comic book medium as a system-environment hybrid - transpires in the present tense, while at the same time being imbued with temporal progression by the four panels framed in the spread. The four panels here function both as a structural grid, transforming the background into gutter, while simultaneously focusing the passage of that very same background into foreground. This oscillation between different temporalities as well as that between background and foreground, and between the materiality of the medium and the mediated content, further stresses the medium as a system-en- 

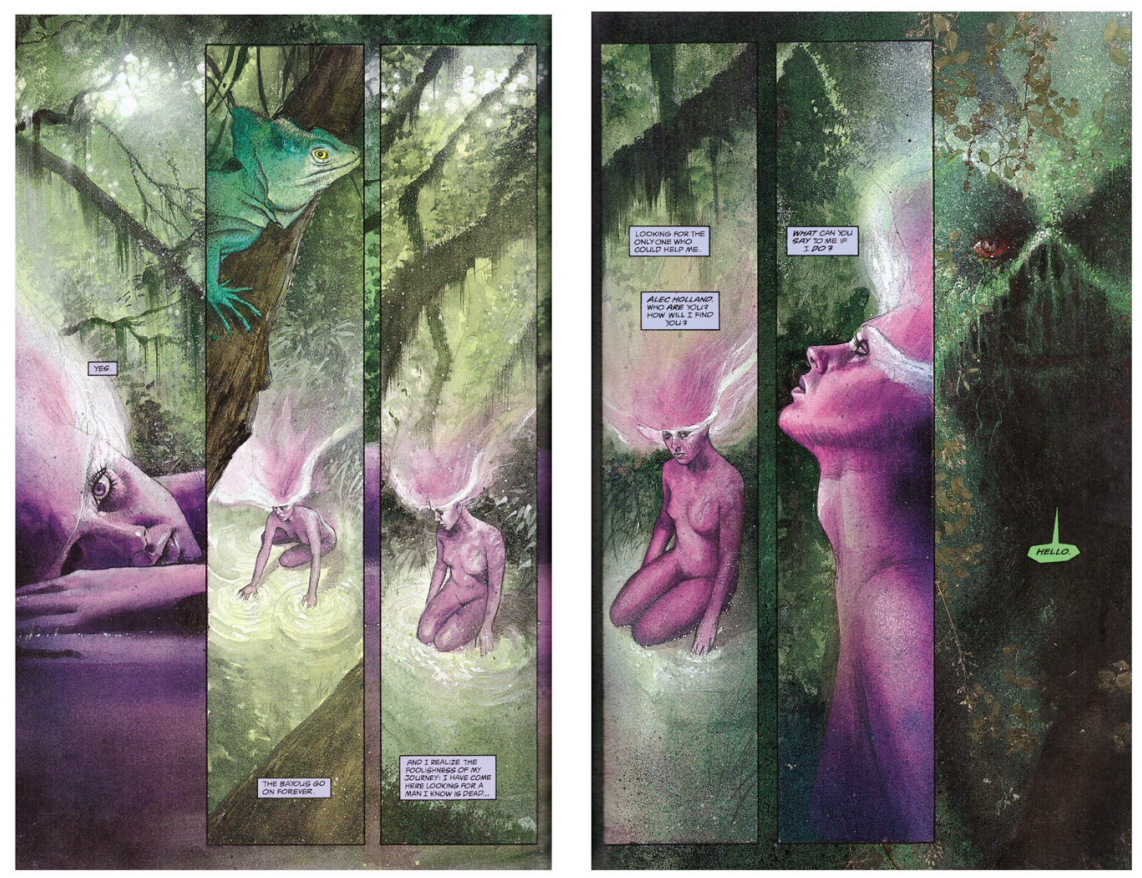

vironment hybrid.6 The circular movement of the spread, which clearly indicates the position of the reader, also emphasizes an embodied experience. In fact, the spread of a comic book presupposes a body holding it, and in that sense delineating an actual circular space. And as the distinctions between background and foreground, between mediating materiality and mediated content, evidently are permeable throughout the spread, there is nothing to say that this permeability would not extend to the body of the reader as well.

But it is not only the adaptation of Moore's rebooted and posthumanist Swamp Thing that sets Black Orchid out as a metafictional and deconstructive comic book. The event of killing the main character at the very beginning of the story also clearly functions both as an intertextual comment on the reboot logic

6 Timothy Morton discusses the tendency to point to the environment of the medium as the medial function of ecomimesis, a concept that has clear affinities with a sympoietic approach to aesthetic experience. See Timothy Morton, Ecology without nature: rethinking environmental aesthetics (Cambridge, Mass.: Harvard University Press, 2007), p $36 f$ 
- in self-conscious dialogue with the participatory culture surrounding the comic book industry - while at the same time establishing a link between the media ecology of the genre and the ecological identity of superheroes in general, and Black Orchid in particular. Memory here also becomes generic: the cultural memory of the superhero genre.

The initial death of Black Orchid is framed by a further insistence on voice as a creative medium. In the dramatic last frames leading up to her death, Black Orchid alludes to the activity of singing, as she makes a prophetic claim: "I will sing to you again. My sis...", before being interrupted, mid-sentence. The brusque silence enforced upon the song comes in the form of an explosion, ripping not only the word "sister" apart, but also transgressing levels between panels, gutters and page layouts. The blast

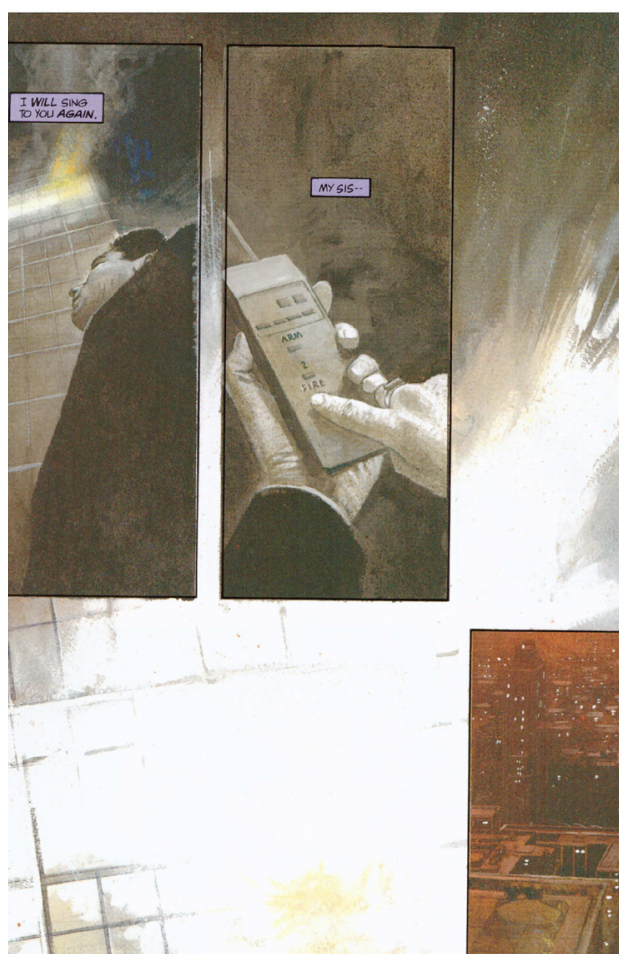
effaces the differentiations of the page that produce meaning, returning it to the supposedly empty whiteness of non-signification. At the same time the temporal progression produced by the succession of panels is broken, retrospectively, when the gutter between the two initial panels is transformed from a material component of the medium, into a site of representation. What was initially read as only the passing of time proves to be an anachronistic intrusion, a breakthrough of a time not yet arrived at. 
The silent explosion is then once again extended into the temporal passage of the white grid of the gutter, as the narration panels from the urban center out into the suburbs and finally lands in the green of the green house. In the following spread,
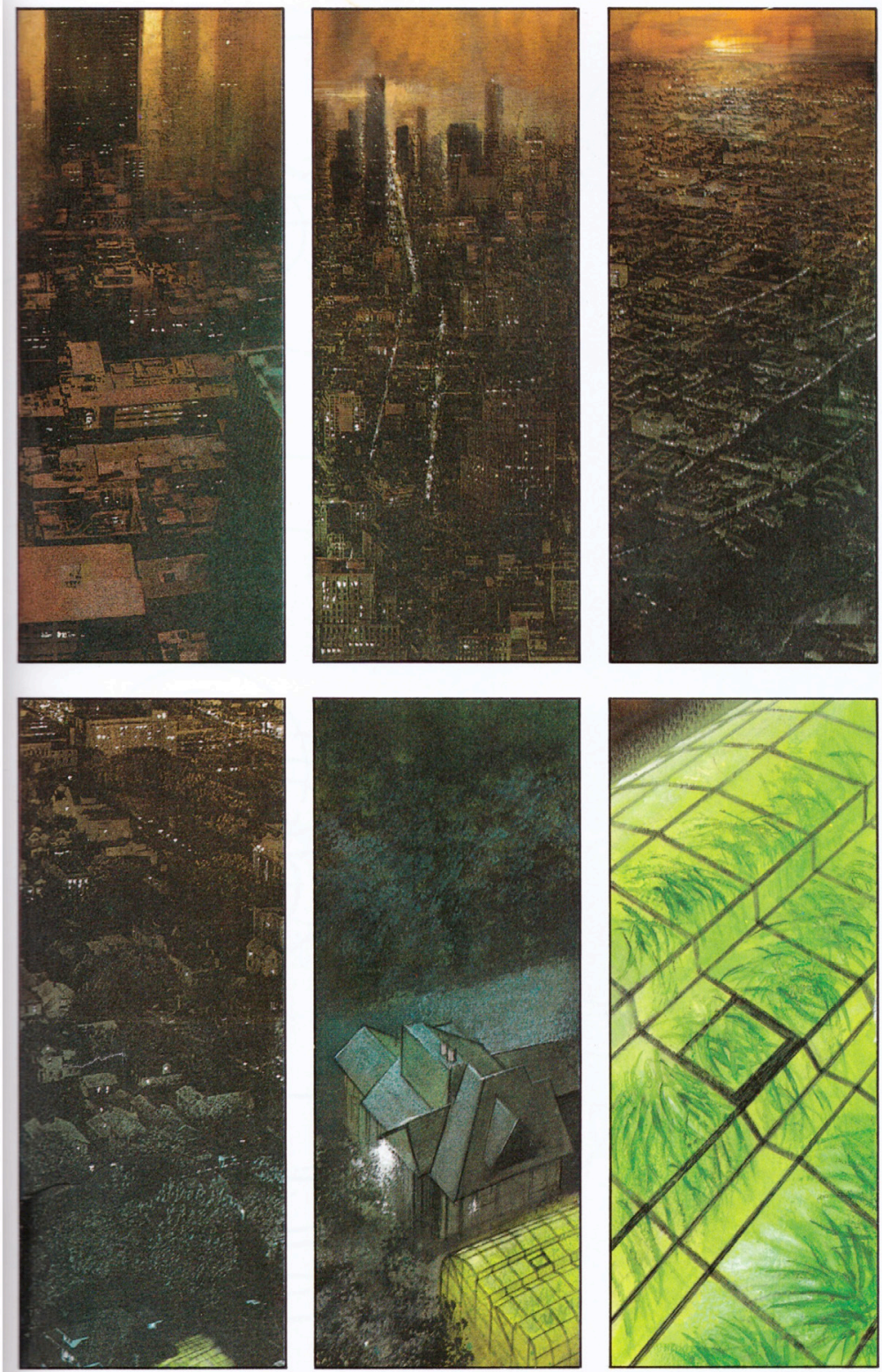
the gutter is extended into panel, and by the appearance of ripples initially attributed the leaking faucet, its temporal function is further enhanced by the temporality of the dripping water, while at the time imbuing this temporal passage with motion and sound. As the sequence progresses the meaning-producing unit of the water ripple is supplemented by the iconography of sound waves, producing an increasingly complex sensorium that culminates in the sudden and violent birth of the new Black Orchid.

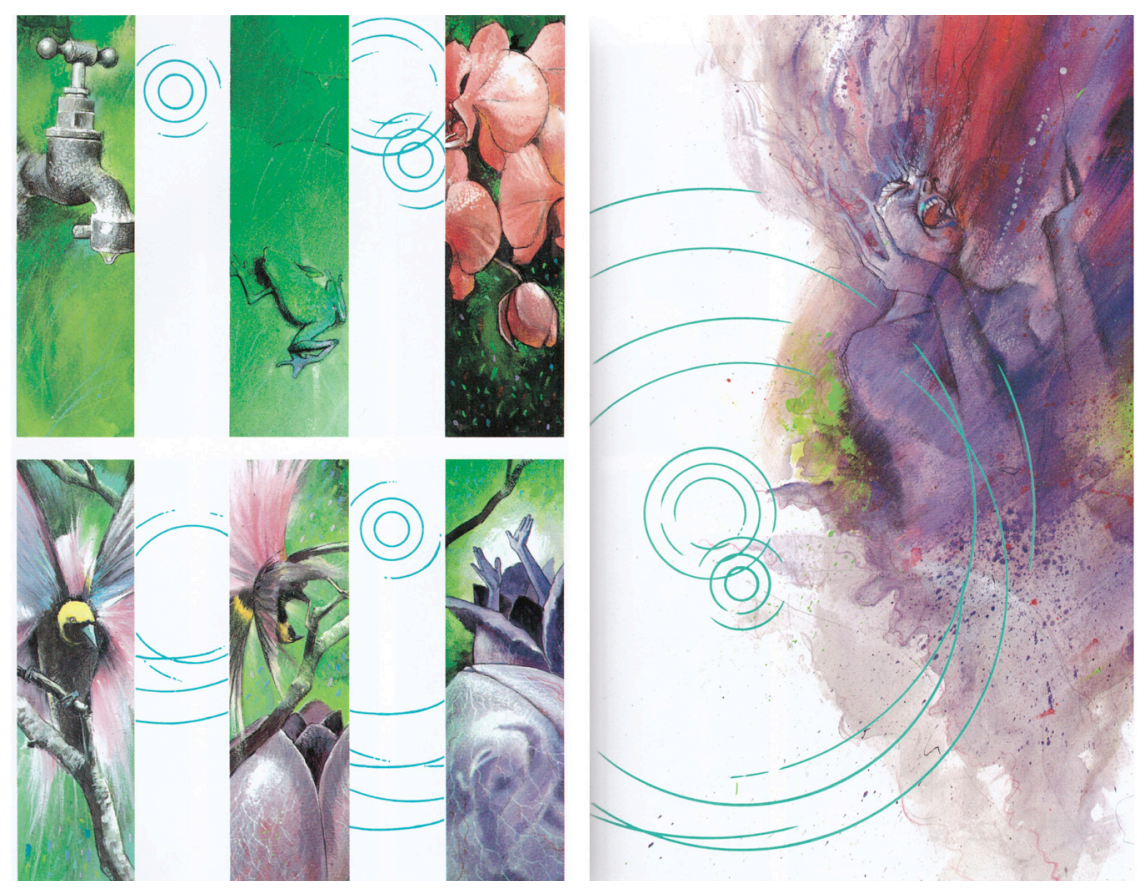

The emergence of the new Black Orchid could here be understood as the emergence of a system-environment hybrid. The becoming of the new body explicitly evokes the materiality of the environment of the medium, in a process delineating and simultaneously producing the senses of the reader. The dropping water of the faucet here translates into the indistinct fluidity of the remediated splash of watercolors from which the silent scream takes form. 
The gutter is a space of utmost importance in the production of meaning in the language of comic books. The gutter is essential in producing temporal succession, and commands the reader to
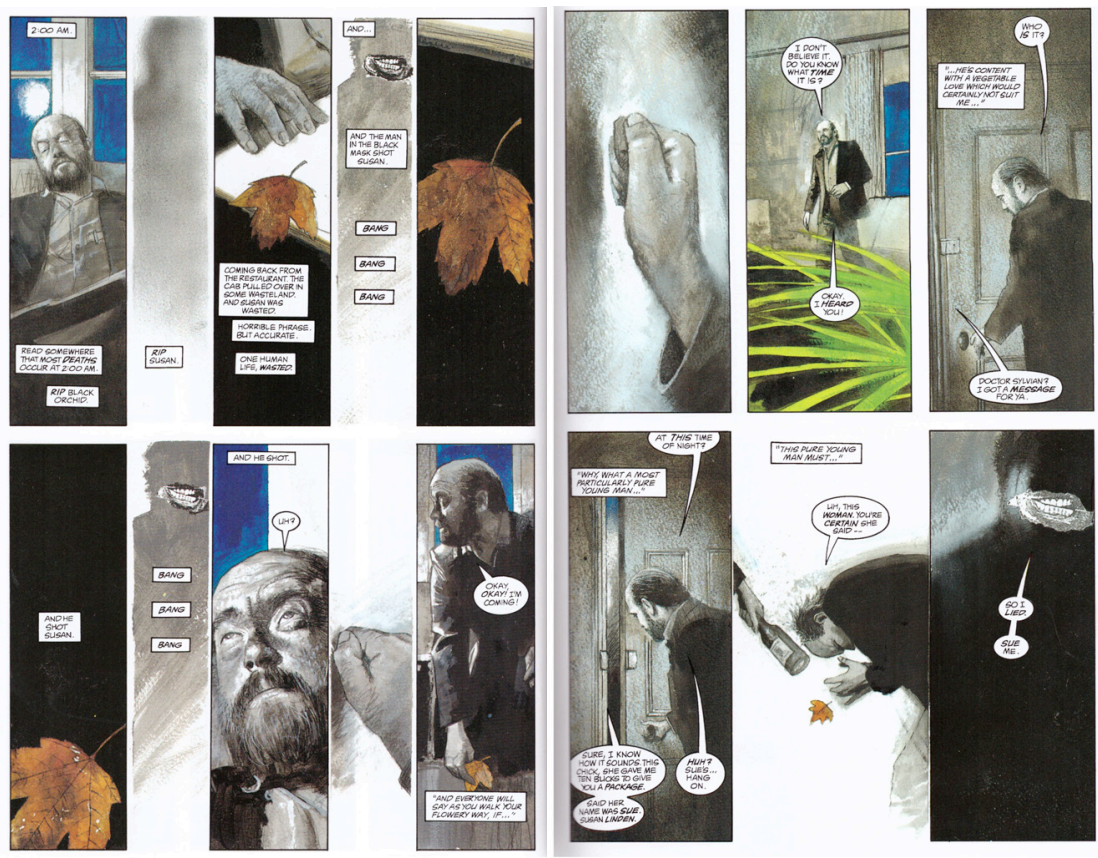

initiate sequential coupling. Here, however, its characteristics are modified. Instead of merely being a space marking the temporality and progression of the reading, functioning as a site where the reader, as an autonomous and disinterested subject, binds together the different units of information provided by the panels into a coherent narrative, the space of the gutter is invaded by residual information.

Emphasizing the feedback between the systemic organization of narrative meaning and the environment of the medium, the sequence becomes an embodied system-environment hybrid. This effect is reached partly by material properties of the medium. It is clear that in this sequence, the medium of the comic book is made into an active participant in the production of 
meaning. The very act of reading, and the bodily movements and sensations that act involves - seeing, touching, hearing - is highlighted.

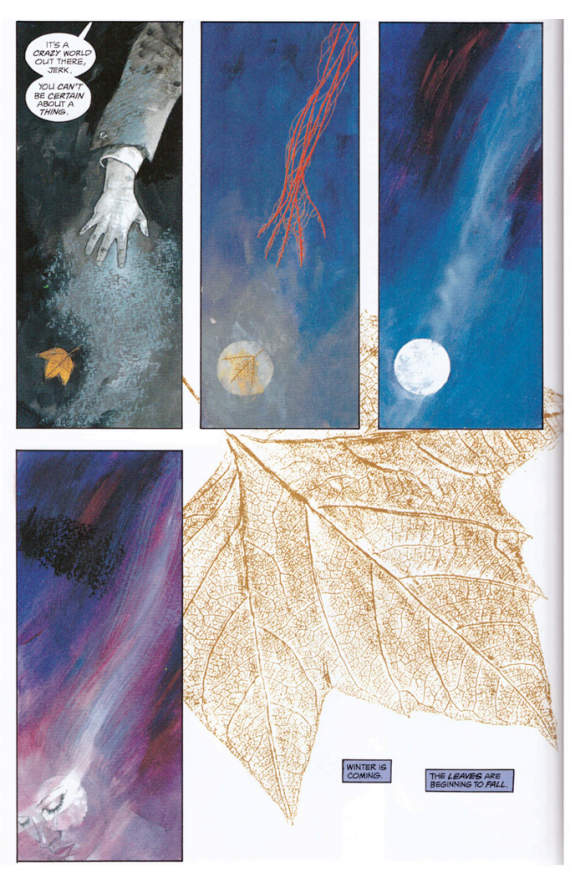

The third sequence I will look at opens in the home of Philip Sylvain. Once again, the gutter is invaded by residual information, producing an afterimage, that only in retrospect is put into context. The invasion of the gutter is paralleled by the invasion of the character Carl Thorne into Philip's home. Carl has recently been released from prison. His appearance coincides with the telling, through the memory of Philip, of the creation of the first Black Orchid hybrid life form. As Carl bludgeons Philip unconscious, the narration dissolves, and the identity of the new Black Orchid coalesces with the backstory of Philip and Susan. [Figure 16] Here the event of the reboot is put to the fore, enforcing configuration as systemenvironmental feedback. It is an event that presupposes uncertainty and openness. As Carl states: "You can't be certain about a thing." Several movements are generated between the four panels and the background. The iconic similarities enfold the two identities of Black Orchid and Philip, juxtaposing the veins, arteries, and capillaries of Philip's arm with the vascular tissues of the dropped maple leaf. At the same time, they are connected by the moon, reflected in the first panel on the floor beside the hand, and in the fourth in Black Orchids visage, connecting the moon with her closed eyes, making the moon a point of entry for the spectator. The moon is further connected to the visual 
sense by the allusion to microscopic vision, produced by the large, transparent, leaf in the background.

While these different units of the page thus are related, they are nevertheless not connected in the form of a narrative. The chronological reading of the panels is here also countered by several lines of flight. The falling leaf in panel one suggests a movement in depth; the arm, the vascular system, the wisp of cloud, and Black Orchid's strangely flowing hair-like outgrowth, suggest an increasing acceleration (the leaf in the moon actually pointing) towards the upper right corner; while the leaf in the background emphatically accentuates unidirectional chronology. The page presents relation as movement and event, rather than structured meaning. This is where the first issue of Black Orchid (1988) ends.

The following sequence, in two spreads, which accordingly opens the second issue of Gaiman and McKean's three-issue reboot, traces the falling leaf, in a montage of juxtaposed bits of memory, belonging to the original Susan Linden, and thematizing voice and autobiographical narrative as something essentially estranged, in which Black Orchid is thinking thoughts not her own, talking to herself in the narrative third person "she has to - I have to get out of this city". The first page in the sequence situates the narrative in the voice and resting visage of Black Orchid. In the second spread, the temporalities of memory and personal history, as well as the different temporalities of the comic book reboot, undergo a

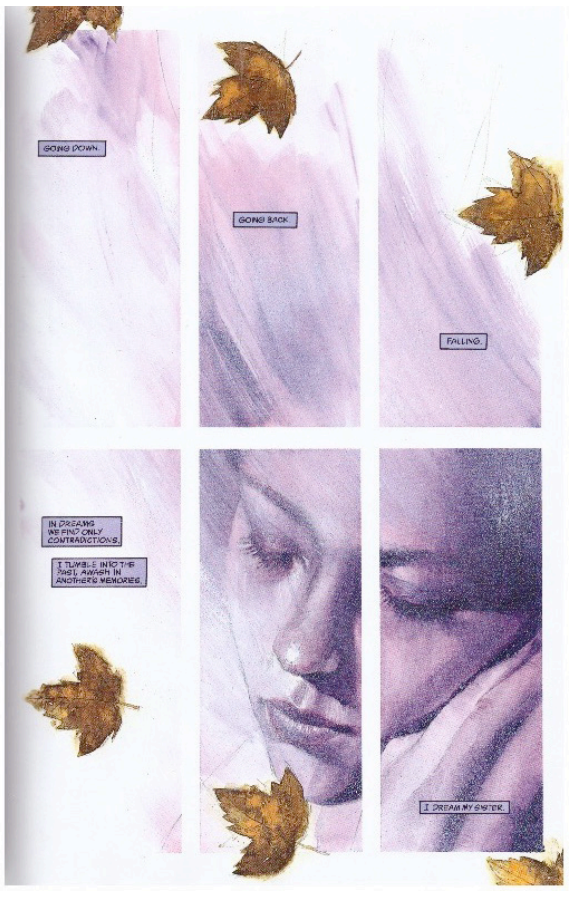


complex layering. The sequences between panels are contrasted to the descending movement of the leaf within the gutter, as well as juxtaposed to the temporalities represented within panels. Memory and identity here also become a question of material storage and material participation, perhaps most evident in the double helix of the DNA spiral, functioning as a hypericon, commenting on the vortex of system-environment feedback. Eventually, the narrative crumbles, the conflicting movements and temporalities take over and the panels dissipate, leaving the

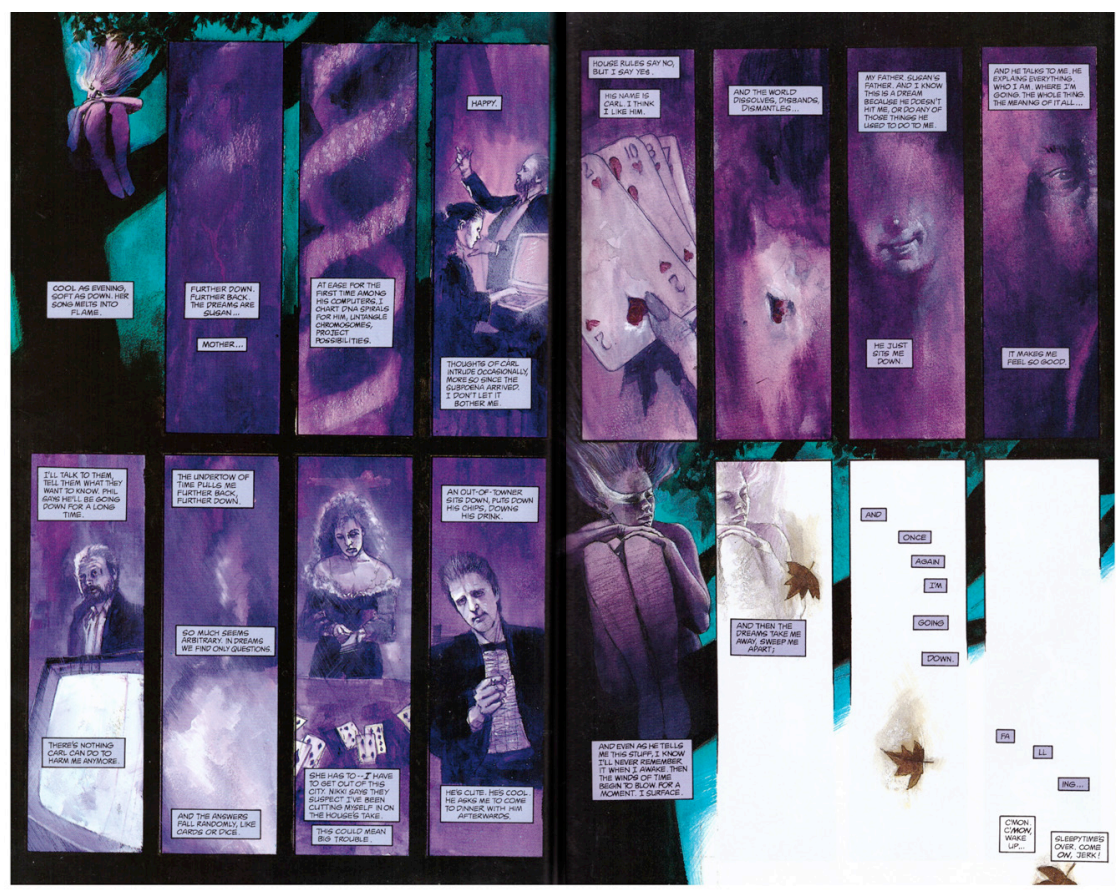

leaf to fall, accompanying the breaking of the last lines of the soliloquy, over the end of the page.

This is where Black Orchid insists on getting: outside the panel, beyond the page, into the green, where human-plant technoculture produces new experience, new cultural expression, and new installments in the ever-expanding franchise of superhero comics. 
Significantly, however, one finds that this is the point - on the precipice of new experience, on the verge of falling outside the frame - at which the voice of the antagonist Carl Thorne calls us back to consciousness, in a rather rude Althusserian interpellation: "Sleepytime's over. Come on, jerk!" Reminding us that the sympoiesis of superheroes is always set within the context of a very real power struggle, where the materiality of the medium is a site for emergent subjectivities, while always already representing the commodification of lived experience.

Reminding us also that the participatory aesthetics of the comic book Black Orchid is about command and control as much as it is about the co-production of ecological creativity.

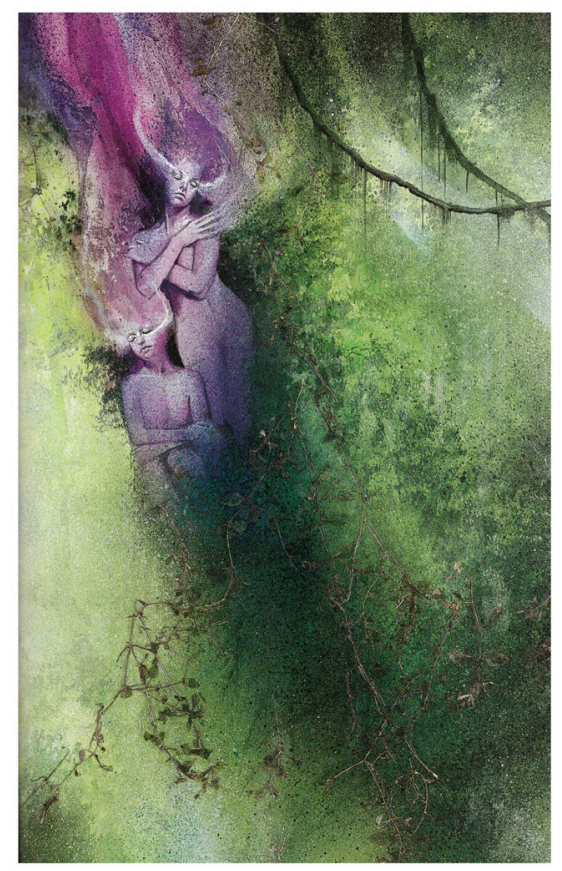

The becoming-with of sympoiesis, following Haraway's argument, emerges here as a model for making worlds - for "wordling" - and for a material semiotics, where matters matter, and meaning, as well as embodied identities, emerge in the form of systemenvironment hybrids. Through the concept of sympoiesis, the agency of material things can supplement the meaningoriented focus of traditional, modernist literary studies, perhaps offering a viable, and ecologically sustainable, trajectory for non-exclusive humanities: non-humanist (and in this sense posthumanist) humanities. Black Orchids in the green of the living. 